\title{
The Knowledge, Attitudes and Practices of Diabetics on Physical Activity at the Marc Sankale Center of Dakar
}

\author{
Sow Djiby*, Diédhiou Demba, Ndour Michel Assane, Diallo Ibrahima Mané, Diouf Mahecor, \\ Ka-Cissé Marie, Sarr Anna, Ndour Mbaye Maimouna \\ Clinique Médicale II, Centre Hospitalier Abass Ndao, UCAD, Dakar \\ Email:^drdjiby@yahoo.fr,dembadiedhiou1976@gmail.com,ibrahimamanediallo@hotmail.fr, \\ michelassanendour@yahoo.fr,mayoumbayee@gmail.com, annasarrr@orange.sn,marikacisse@gmail.com
}

How to cite this paper: Djiby, S., Demba, D., Assane, N.M., Mané, D.I., Mahecor, D., Marie, K.-C., Anna, S. and Maimouna, N.M. (2018) The Knowledge, Attitudes and Practices of Diabetics on Physical Activity at the Marc Sankale Center of Dakar. Open Journal of Internal Medicine, 8, 33-41. https://doi.org/10.4236/ojim.2018.81005

Received: October 30, 2017

Accepted: January 21, 2018

Published: January 24, 2018

Copyright $\odot 2018$ by authors and Scientific Research Publishing Inc. This work is licensed under the Creative Commons Attribution International License (CC BY 4.0).

http://creativecommons.org/licenses/by/4.0/

\begin{abstract}
Introduction: The objective of that study was to evaluate diabetics knowledge, attitudes and practices on physical activity. Patients and Methods: That study has concerned 200 diabetics at Marc Sankale antidiabetic Center of Abass Ndao Hospital in Dakar. Women represent $76 \%$ with a sex ratio M: F0.13. The average age is 54 years with extremes of 4 to 84 years. The housewives are $29 \%$ and among them 15\% haven't any professional activity. $45.07 \%$ of the population is illiterate. In our study, $63.13 \%$ of patients have low socio economic level. In our series, the majority of patients is type 2 diabetes (89.5\%). The diabetes evolution time is about 8 years inferior to $7 \%$ in 84 patients. In our study obesity is noted in $17.20 \%$ of cases. The HTA is present in $56 \%$ of cases. $54 \%$ of the studied population presents a dyslipidemia. Physical activity is practiced in $81 \%$ of patients. In our study the doctor' advice motivates the half of our patients to practice physical activity (62.26\%). The lack of time (43.2\%) and volution (8.1\%), the useless character of physical activity (2.7\%) and the patients' health state $45.9 \%$ are the obstacles to the practice of physical activity. The average frequency of physical activity practiced by patients is about 4 times a week with extremes ranging from 1 to 7 stages a week. The average time of activity practiced by patients is $39.72 \%$ with extremes ranging from 10 to $150 \mathrm{mn} .87 \%$ of patients practice physical activity at least 3 times a week. The main risks noted from intense physical activity in diabetics are hypertension $39.0 \%$, ortestic hypertension $3.0 \%$. In the contrary $58.8 \%$ of patients ignore the answer. Conclusion: Our study demonstrates the ignorance of diabetics on physical activity. Therefore it would be necessary to reinforce the training mainly therapeutic education in the patients taken into account.
\end{abstract}

\section{Keywords}

Diabetes Mellitus, Risk Factor, Knowledge, Physical Activity, Senegal 


\section{Introduction}

Diabetes is a public health problem due to medical, social and financial implications.

The International Diabetes Federation (IDF) 2017 estimates report a prevalence of 425 million of diabetics in the world. Prevalence in sub-Saharan Africa increased from $4.8 \%$ to $5.7 \%$ [1]. In Senegal it is estimated to $3.2 \%$ [2]. The diabetes mellitus is known by its morbidity and mortality risk almost in association to cardiovascular risk factors. Except the drug treatment, the taken responsibility is a necessity to inform and educate patients in order to participate actively to diabetes management. There is progressively a proof that the education of patients is a most efficient mean to reduce diabetes complication and management [3]. The education will be efficient if we know the characteristics of patients in terms of knowledge their attitudes and practices in diabetes. According to what we know, no study has been done on this domain on Senegal. In this way the objective of this study is to evaluate knowledge, attitudes and practices of diabetics on physical.

\section{Patients and Methods}

There was a cross, descriptive and analytic study done from March 1st 2015 to April 15th 2015 in the reference Center of diabetes taken into account on physical activity.

Criterion for inclusion: It concernsall type 2 and 1 diabetics who come on routine consultation at Marc Sankale Center during the study period regardless diabetes ancientness and the existence or not of degenerative complication without hindrance and the acceptation to participate to the study.

Criterion for exclusion: Patients that have other diabetes forms: gestational diabetes, secondary diabetes, those who refuse to be part of the study. Patients received in curing room and in other consultation (emergencies). Standard questionnaires were established to serve as a selective data bases. It was proposed to question by direct interrogation. The questionnaires management has been realized through interview with patients or accompanier. Questionnaires will be done in an anonymous way, patients identification will be done thanks to its medical dossier number. The following dossier reports clinical and Paraclinical elements of patient during the following were associated. The collective data required was the followings:

Epidemiological data: Age; sex; antecedents; profession, matrimonial status, address; schooling level; socioeconomic level.

Cardio vascular risk factor study was taken into account in our study. Hypertension; smoking; microalbuminuria inferior to $30 \mathrm{mg} / 24 \mathrm{~h}$ without urinary infection; dyslipidemia researched away from acute pathology were defined by the presence of one or several anomalies or an antecedent known through dyslipidemia according to national Cholesterol Education program Adult Treatment Panel (NEPAT) [4] and corporal mass clue according to classification of the International Obesity Task Force [5]. 
Study of diabetes mellitus: It concerns diagnose age; the type of diabetes and its ancientness. Diabetes glycemia balance and its chronic complications were also evaluated. The typology of diabetes in the lack of immunology and that of the dosage of the peptide $\mathrm{C}$ was presumptively based on clinic and progressive arguments (age of the patient and his morph type symptoms installation Deadline, familial antecedent and evolution under treatment).

SUPPORT: It concerns realization of diet education and medical treatments. Patients were glycemic balance if glycemia during the fast is inferior to 1.21 $\mathrm{mg} / \mathrm{dl}$ and the $\mathrm{HbA1C}$ inferior to $7 \%$ according to recommendations of American Diabetes Association [6].

Physical activity study: Knowledge, practical attitudes of patients were evaluated according an inquiry toward then [7].

KNOWLEDGE represents an amount of things known; knowledge and science. It is a capacity of self-representation, a way of perceiving. The knowledge in behavior profitable don't implicate automatically the application of behavior .The degree of knowledge noticed helps know domain where efforts in terms of information and education should be done.

ATTITUDES: Attitude is a way to be posture. There are tendency and dispositions. There is variable intermediary between the situation and the response of that situation. It helps explain that among the possible practices of a subject under a stimulus, this can adapt any or any other practice.

PRACTICES or behaviors are observed actions from a person in response to stimulus.

It concerns the reality. It is the know-how.

This card is approved by the Hospital Ethics Committee.

The input and the exploitation have been accomplished by software like SPSS Statistic 18.0.

\section{Results}

\subsection{Sociodemographic and Clinical Profile of Patients on Inclusion}

This study involved a sample of 200 diabetic patients followed at the Marc Sankale antidiabetic center of the Abass Ndao hospital in Dakar. Women represent $76 \%$ of cases (152 patients), and men 48 cases $24 \%$ with a sex ratio (M: F) of 0.31 . The average age is 54 years with extremes of 4 to 84 years. Diabetics were older than 50 years in 131 cases or $65.5 \%$. Housewives made up $29 \%$, shopkeepers $20 \%$ and $15 \%$ have no professional activity. For the level of education $45.7 \%$ of the population is out of school, primary schooling (23.6\%), secondary schooling (16.6\%), and only $14.1 \%$ of cases have a level of education. High study. In our study $63.13 \%$ of patients have a low socio-economic level. The bride and groom are the most represented with $74.5 \%$.

\subsection{Study of Diabetes Mellitus}

In our series, the majority of patients with diabetes are type 2 (89.50\%), type 1 
diabetic patients represent $10.50 \%$. In our study population, the duration of diabetes is approximately 8 years. $38.60 \%$ of patients have seniority between $0-5$ years, $36.40 \%$ between $11-26$ years and $25.0 \%$ have diabetes for more than 10 years. In our series, more than half of the patients discovered their diabetes due to functional signs (71\%), $27.50 \%$ following a systematic assessment and $1.50 \%$ with a ketoacidocetosis. Among the 188 patients in our population who did this examination, HbAlc was equal to 7 in 12 patients, $6 \%$, less than $7 \%$ in 84 patients, $42 \%$ and greater than $7 \%$ in 92 patients, $46 \%$. Table 1 shows the characteristics of the study population at baseline.

\subsection{Study of Cardiovascular Risk Factors}

In our study, $43.20 \%$ of patients have a normal weight, $33.30 \%$ are overweight, obesity is noted in $17.20 \%$ of cases and $6.30 \%$ of diabetic patients are lean. In our study, women are more obese than men with $20 \%$ versus $8.5 \%$. In our series, hypertension is present in $50 \%$ of cases. $54.4 \%$ of the population studied have dyslipidemia. The concept of active smoking is found in $1.5 \%$ of our patients. In our study, 3\% had to use alcohol, of which $1 \%$ still drinks and $2 \%$ stopped, compared to $97 \%$ of patients who never drank alcohol.

\subsection{Study of Physical Activity}

Physical activity is practiced in $81.5 \%$ of patients. It is practiced regularly in $79.80 \%$. Among the patients with physical activity, $81.5 \%$ also follow a low carbohydrate diet. Among the patients practicing a physical activity, $47.9 \%$ follow a hypo caloric diet. Of the patients with physical activity, $53.4 \%$ follow a low sodium diet. In our series, the doctor's advice is the main motivation to practice a

Table 1. Socio-demographic and clinical characteristics of the study population.

\begin{tabular}{cc}
\hline Characteristics of Patients with Inclusion & \\
Average age & 54 years \\
men $\geq 50$ years & $65.5 \%$ \\
Women > 60 years & $76 \%$ \\
Sexe ratio (M: F) & 0.31 \\
Type 2 diabetes & $89.5 \%$ \\
Household & $29 \%$ \\
Not educated & $45.7 \%$ \\
Low socio-economic level & $63.13 \%$ \\
Average seniority diabetes & 8 years \\
HbAlc $>$ 7\% & $46 \%$ \\
High blood pressure & $50 \%$ \\
Overweight and obesity & $50.5 \%$ \\
Active smoking & $8.8 \%$ \\
Dyslipidemia & $54.4 \%$ \\
\hline
\end{tabular}


physical activity in more than half of our patients with $62.26 \%$, for pleasure $19.34 \%$ and for health $18.40 \%$. In our study, $51.50 \%$ started to practice sport after the discovery of diabetes, $38.0 \%$ before the discovery of the disease and $10.40 \%$ at the time of discovery. Of the 163 participants who participated in physical activity, $86.50 \%$ or 141 patients opted for walking, $11.66 \%$ or 19 patients for the race, $1.23 \%$ or 2 patients for cycling, and only 1 patient was $0,61 \%$ for football. During their physical activity, $77.27 \%$ of patients wear sandals, $15.15 \%$ of sports shoes and $7.58 \%$ of slippers. Barriers to practicing physical activity are mainly lack of time (43.2\%), lack of will (8.1\%), uselessness of physical activity $(2.7 \%)$ and the state of health of the patients $(45.9 \%)$. The average frequency of physical activity practiced by patients is about 4 times a week with extremes ranging from 1 - 7 sessions/week. The average duration of the activity practiced by patients is $39.72 \mathrm{~min}$ with extremes ranging from $10-150 \mathrm{~min} .87 .8 \%$ of patients are physically active at least 3 times a week for at least 30 minutes. Type 1 diabetics practice sports in $85.7 \%$ compared to $81 \%$ in type 2 . For $94 \%$ of patients, the type of physical activity most indicated for diabetics is endurance (walking). The main risks identified in cases of intense physical activity in diabetics are hypoglycemia (39.0\%) and orthostatic hypotension (3.0\%). On the other hand, $58.0 \%$ of patients admitted not to know the answer. For $42.5 \%$ of patients the minimum frequency of physical activity is 3 times/7 days. The benefit of physical activity is the drop in blood glucose is most cited by patients with $70.59 \%$, for weight loss (18.01\%) and regulation of blood pressure (11.40\%). In our series $90.09 \%$ of patients consider physical activity as an integral part of diabetes treatment; $2.36 \%$ as an optional option and $7.55 \%$ as leisure. $68.0 \%$ of patients do not want a material and/or professional support to improve their physical activity practice against $32.0 \%$ of patients who wish.

\section{Discussion}

This study carried out in diabetics focused on the assessment of diabetics' knowledge of physical activity which is still insufficient despite the psychic activities devoted to them. To our knowledge very few studies on physical activity in diabetes have been performed. Most studies focused on epidemiological aspects and complications.

\subsection{Cardiovascular Risk Factors}

In our study, obesity is noted in $17.20 \%$ of cases. Women are more obese than men with $20 \%$ against $8.5 \%$. HTA is present in $50 \%$ of cases and $54.4 \%$ of the population studied have dyslipidemia. Physical activity also allows for better control of risk factors: High blood pressure [8] [9], dyslipidemia [10], diabetes with decreased insulin resistance [11], overweight [12]. Obesity and physical inactivity thus contribute independently to the development of T2D, but the importance of the risk of obesity is greater than that due to insufficient physical activity. Obese subjects also benefit from a reduced risk of T2D when they have 
regular physical activity. According to the study (Nurses Health Study on American nurses with no history of diabetes, cardiovascular pathology or cancer), followed for 16 years [13]; the relative risk of T2D is: 16.75 for obese women with no physical activity and 10.74 for women with regular but obese physical activity.

\subsection{Study of Physical Activity}

Physical activity is practiced in $81.5 \%$ of patients. In the Diabasis survey conducted by TNS Healthcare-Sofres, a sample of 12,000 people aged 45 and over showed that only $30 \%$ of diabetics were physically active [14]. In another study conducted in Waghodia, India, $74 \%$ of patients had regular physical activity [15]. In South Africa the study by Shilubane et al. [16] shows that nearly 41 (41.0\%) of patients exercised, while 15 (15.0\%) did not believe in physical exercise. This observation can be explained by the fact that the methodologies applied are different, especially in terms of the population surveyed. Non-practicing subjects need to be educated in order to strengthen their management. In our study, the average age is 54 years and the subjects surveyed were older than 50 years in $65.5 \%$. The housewives accounted for $29 \%$. In Africa, walking and domestic activities are considered physical activity. In our series, doctor's advice is the main motivation for practicing physical activity in more than half of our patients with $62.26 \%$. In the study by Shilubane and al [16] $44.0 \%$ of Patients had no information on whether diabetic patients could benefit from physical exercise Thus, listening, education and information skills of the doctor are very important at the discovery of diabetes. In our study $51.50 \%$ started to practice sport after the discovery of diabetes, and $10.40 \%$ at the time of discovery. Eating is the most frequently and easily modified as the practice of physical activity. This one is much more difficult to start. This fact should motivate early follow-up, if possible from the onset of illness, with consultations devoted to therapeutic education, to facilitate changes in lifestyle and in particular the practice of physical activity [14]. The patients who exercise it, $86.50 \%$ opt for walking and $77.27 \%$ of patients wear sandals during their physical activity. These can be a source of foot infections and can lead to foot amputation. Therapeutic education is necessary for shoes adapted to physical activity. Educational level: $45.7 \%$ of the population is out of school. The most important factor is the low level of education, only $10 \%$ were graduates and nearly $37 \%$ were completely illiterate. Therefore, illiteracy may be the most important obstacle in the management of diabetes in these patients. It is right that education for vulnerable communities can become a cost-effective public health strategy [17]. These results have been corroborated by studies in Debré Tabor, Malaysia and India, who said that those belonging to higher socioeconomic groups had more knowledge about MD [18] [19].

Diabetes is associated with increased cardiovascular risk. In fact, cardiovascular diseases are the main cause of morbidity and mortality in T2D patients and 
myocardial disorders leading to heart failure [20]. The prescription of physical activity in diabetics is met with some reluctance by fear of provoking an acute cardiac event. Barriers to practicing physical activity are mainly lack of time (43.2\%), uselessness of physical activity $(2.7 \%)$ and the state of health of patients. patients (45.9\%). The average frequency of physical activity practiced by patients is about 4 times a week. It is recognized that regular PA can reduce early mortality, particularly cardiovascular mortality by $20 \%$ to $30 \%$ [21]. This may require a period of education with supervised sessions, leading to patient autonomy in management. of his effort, especially through the teaching of self-perception of the intensity of the exercise.

The average duration of the activity practiced by patients is $39.72 \mathrm{~min}$ with extremes ranging from 10 - $150 \mathrm{~min}$. The main risks identified in cases of intense physical activity in diabetics are hypoglycemia (39.0\%) and orthostatic hypotension (3.0\%). The benefit of physical activity is the drop in blood glucose is most cited by patients with $70.59 \%$, for weight loss $(18.01 \%)$ and regulation of blood pressure (11.40\%). A recent study in type 2 diabetics showed a decrease in plasma glucose concentration over 24 hours and postprandial glucose peaks after 6 weeks of EIHI [22]. However, these effects of physical activity on mortality and morbidity are well demonstrated in the general population [23].

Thomas and al. in their meta-analysis demonstrated a beneficial effect of regular physical activity on the glycemic balance of T2D patients with an average decrease [24]. HbA1c $-0.6 \%$ and no hypoglycemia could be noted. On the contrary, exercise is important because of its effect of lowering blood sugar levels and reducing cardiovascular risk factors; while physical inactivity increases the risk of type 2 diabetics [25]. This assertion is also affirmed by Sellers [26] who has demonstrated the importance of exercise as "minimizing abnormal stresses placed on the body and helping individuals to adapt and adapt to everyday life and presenting psychological benefits such as the promotion of health and well-being". In addition, local behavioral practices and beliefs, as well as internal and external barriers to change specific to the community, contribute to the prevalence of type 2 diabetes mellitus by promoting non-participation in physical activity [27]. In our study the imbalance of diabetes is noted in $46 \%$ of patients. Taking into account the brakes and the contributing factors constitutes the base of the educational diagnosis concerning the accompaniment to the physical activity [28].

\section{References}

[1] International Diabetes Federation. IDF Diabetes Atlas. 8th Edition. Brussels, Belgium: International Diabetes Federation, 2017. http://www.diabetesatlas.org/resources/2017-atlas.html

[2] Diop, S.N. and Diedhiou, D. (2015) Promoting Access to Therapeutic Education and Reducing Inequalities: Intervention Analysis Conducted in Africa and the Indian Ocean. Metabolic Disease Medicine, 9, 123-129.

[3] Mazzuca, S.A., Moorman, N.H. and Wheeler, M.L. (1986) The Diabetes Education 
Study: A Controlled Trial of the Effects of Education on Diabetes. Diabetes Care, 9, $1-10$.

[4] National Cholesterol Education Program, Adult Treatment Panel II NCEP-ATP III (Accessed 01 MAY 2015). http://www.lipidcenter.com

[5] Cole, T.J., Bellizzi, M.C., Flegal, M.E., et al. (2000) Establishing a Standard Definition for Overweight and Obesity Worldwide: International Survey. BMJ, 320, 1240-1243. https://doi.org/10.1136/bmj.320.7244.1240

[6] American Diabetes Association (2003) Screening for Type 2 Diabetes/Clinical Practice Recommendations/Position Statement. Diabetes Care, 21, 21-26.

[7] Doctors of the World. Data Collection - Quantitative Methods - The Example of the Surveys Cap (Knowledge, Attitudes and Practices).

www.medecinsdumonde.org/Publications/Guides-a-1-usage-des-professionnels-de-1 -humanitaire

[8] Pescatello, L.S., Fargo, A.E., Leach Jr., C.N. and Scherzer, H.H. (1991) Short-Term Effect of Dynamic Exercise on Arterial Blood Pressure. Circulation, 83, 1557-1561. https://doi.org/10.1161/01.CIR.83.5.1557

[9] Turner, M.J., Spina, R.J., Kohrt, W.M. and Ehsani, A. (2000) Effects of Endurance Exercise Training on Left Ventricular Size and Remodeling in Older Adults with Hypertension. The Journals of Gerontology: Series A, 55, 245-251. https://doi.org/10.1093/gerona/55.4.M245

[10] Sdringola, S., Nakagawa, K., Nakagawa, Y., Yusuf, S.W., Boccalandro, F., Mullani, N., et al. (2003) Combined Intensive Lifestyle and Pharmacologic Lipid Treatment. Further Reduction of Coronary Events and Myocardial Infusion Abnormalities Compared with Usual-Care Cholesterol-Lowering Drugs in Coronary Artery Disease. Journal of the American College of Cardiology, 41, 263-272. https://doi.org/10.1016/S0735-1097(02)02693-1

[11] Paffenbarger, R.S., Lee, I.M. and Kampert, J.B. (1997) Physical Activity in the Prevention of Non-Insulin-Dependent Diabetes mellitus. World Review of Nutrition and Dietetics, 82, 210-218.

[12] Savage, P.D., Brochu, M., Poehlman, E.T. and Ades, P.A. (2003) Reduction in Obesity and Coronary Risk Factors after High Caloric Exercise Training in Overweight Coronary Patients. American Heart Journal, 146, 317-323. https://doi.org/10.1016/S0002-8703(02)94706-X

[13] Rana, J.S., Li, T.Y., Manson, J.E. and Hu, F.B. (2007) Adiposity Compared with Physical Inactivity and Risk of Type 2 Diabetes in Women. Diabetes Care, 30, 53-58. https://doi.org/10.2337/dc06-1456

[14] Virally: Diabasis Survey: Perception and Experience of Diabetes by Diabetic Patients: Medicine of Metabolic Diseases. December 2009, Vol. 3, No 6.

[15] Rathod, G.B., Rathod, S. and Parmar, P. (2014) Study of Knowledge, Attitude and Practice of General Population of Waghodia towards Diabetes Mellitus. International Journal of Current Research and Review, 6, 63-68.

[16] Shilubane, H., et al. (2016) Beliefs and Practices of Diabetes Patients in Vhembe District of Limpopo Province. African Journal of Primary Health Care \& Family Medicine, 8, 949. https://doi.org/10.4102/phcfm.v8i2.949

[17] Balagopal, P., Kamalamma, N., Patel, T.G. and Misra, R. (2008) A Community-Based Diabetes Prevention and Management Program in a Rural Village in India. Diabetes Care, 31, 1097-1104.

[18] Minhat, H.S. and Hamedon, T.R. (2014) Understanding towards Diabetes Mellitus 
among Rural Adult Community in Malaysia. World Journal of Medical Sciences, 11, 217-221.

[19] Rani, P.K., Raman, R., Subramani, S., Perumal, G., Kumaramanickavel, G. and Sharma, T. (2008) Knowledge of Diabetes and Diabetic Retinopathy among Rural Populations in India, and the Influence of Knowledge of Diabetic Retinopathy on Attitude and Practice. Rural and Remote Health, 8, 838.

[20] Haffner, S.M., Lehto, S., Rönnemaa, T., et al. (1998) Mortality from Coronary Heart Disease in Infants and Infants. The New England Journal of Medicine, 339, 229-234. https://doi.org/10.1056/NEJM199807233390404

[21] Lee, I.M. and Skerrett, P.J. (2001) Physical Activity and All-Cause Mortality: What Is the Dose-Response Relationship? Medicine and Science in Sports and Exercise, 33, S459-S471. https://doi.org/10.1097/00005768-200106001-00016

[22] Little, J.P., Gillen, J.B., Percival, M.E., et al. (2011) Low-Volume Highintensity Interval Reduction of Hyperglycemia and Increases Muscle Mitochondrial Capacity in Patients with Type 2 Diabetes. Journal of Applied Physiology, 111, 1554-1560. https://doi.org/10.1152/japplphysiol.00921.2011

[23] National Institute of Health and Medical Research (INSERM) (2008) Collective Expertise. Physical Activity-Contexts and Effects on Health. Collection Expertise Collective. INSERM Publishing, Paris.

[24] Thomas, D.E., Elliott, E.J. and Naughton, G.A. (2006) Exercise for Type 2 Diabetes Mellitus. The Cochrane Database of Systematic Reviews, 3, CD002968. https://doi.org/10.1002/14651858.CD002968.pub2

[25] Bazzano, L., Serdula, M. and Liu, S. (2005) Prevention of Type 2 Diabetes through Diet and Lifestyle Modification. The Journal of the American College of Nutrition, 24, 310-319. https://doi.org/10.1080/07315724.2005.10719479

[26] Sellers E. (2010) Exercise and Type 2 Diabetes: American College of Sports Medicine and the American Diabetes Association: Statement of Common Position. Medicine \& Science in Sports \& Exercise, 42, 2282-2303.

[27] Anderson, C., van Vuuren, A.J. and Leamonth, D. (2013) Preventing Type 2 Diabetes in South Africa-A Focus on Facilitating Behavioral Change in Physical Activity in Young Peri-Urban Women. Online Readings in Psychology and Culture, 10. https://doi.org/10.9707/2307-0919.1122

[28] Ciangura, C. and Oppert, J.M. (2009) Therapeutic Education in the Management of Metabolic Diseases: The Role of Physical Activity. In: Simon, D., Traynard, P.Y., Bourdillon, F., Gagnayre, R. and Grimaldi, A., Eds., Therapeutic Education: Prevention and Chronic Disease, 2nd Edition, Masson, Paris, 127-137. 